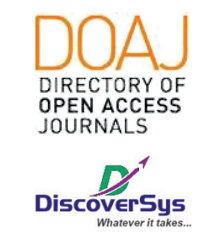

Published by DiscoverSys

\section{Major risk factors that are potential for infertility among male semester 3 and 5 medical students, Faculty of Medicine, Udayana University year 2017}

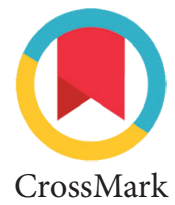

\author{
Yashni Subramaniam, ${ }^{1 *}$ Nyoman Mangku Karmaya ${ }^{2}$
}

\section{ABSTRACT}

Introduction: A couple being unable to get pregnant result out of unprotected sex and have been trying for one year is defined as the inability to conceive or infertile. Other reasons can be due to the male lifestyle itself, for example obesity, alcohol consumption and also smoking. This study aims to look for various things that might be risk factors for infertility in male students of semester III and V, in the Faculty of Medicine of Udayana University in 2017.

Method:This study used a descriptive cross-sectional design carried out during the 2017 period using the questionnaire given to respondents, a total of 116 male respondents in this study. Identification of lifestyle that can be a risk factor for infertility was assessed in all respondent.
Result: Through this research, it can be known that lifestyle risk factors that cause infertility are using a laptop on the lap for hours $(29.3 \%)$, injury in groin area $(14, \%)$, alcoholism $(11.2 \%)$, continuous fast food consumption (12.1\%), and obesity (6.9\%), and active smoker (1.7\%). In the other side of the person still doing a sedentary lifestyle and low physical activity.

Conclusion: Sedentary lifestyles with low physical activity are common lifestyle finding among medical students so that this can be a lifestyle that becomes a risk factor for the onset of infertility.
${ }^{1}$ Faculty of Medicine, Udayana University, Bali-Indonesia ${ }^{2}$ Anatomy Department, Faculty of Medicine, Udayana University, Bali-Indonesia

\section{*Correspondence to:} Yashni Subramaniam, Faculty of Medicine, Udayana University, Bali-Indonesia yasenia.meshach19@gmail.com

Received: 2019-03-09 Accepted: 2019-04-11 Published: 2019-08-01

Keywords: infertility, lifestyle, sedentary, medical student.

Cite This Article: Subramaniam, Y., Karmaya, N.M. 2019. Major risk factors that are potential for infertility among male semester 3 and 5 medical students, Faculty of Medicine, Udayana University year 2017. Intisari Sains Medis 10(3): 511-514. D0I: 10.15562/ism.v10i3.433

\title{
INTRODUCTION
}

A couple is defined as infertile if no conception results after one year of normal sexual practice without contraception. Infertility is defined as the inability to conceive after one year of unprotected sex, regular sexual intercourse. It affects one in every six couples of childbearing age in the U.S. There are two types of infertility. ${ }^{1}$ One, permanent infertility whereby, the male is unable to reproduce and never be able to bear children. The second is, couples with one child and are unable to bear the following one due to infertility. In $40 \%$ of the cases, the problems are related to the men and in $30 \%$. Birth of an infant can strengthen the family basis, meet the emotional need of the people and finally lead to renewal and continuity of the generation. Some studies have proven that the diagnosis of infertility is male infertility, it would have more negative response in men and would cause exacerbation in depression, social aversion and failure. ${ }^{2}$ They would rather suffer anxiety, isolation, self-blame, and inadequate sexual power and feeling that their identity and manhood are not perfect. ${ }^{3}$

80 million people all over the world are suffering from infertility. Based on a survey conducted using the Colaizzi Method, the results were expressed in four main concepts, individual stress, challenge in communication, problems associated With treatment process and the effects of beliefs and religious attitude. ${ }^{1}$ Other factors that may be a contribution due to Male Infertility is the loneliness feeling, disbelief, denial, feeling of inner and external challenge. Many are unaware of the treatments available and presume it costs is high and poor performance of the medical team that fail to deliver important messages to their patients. ${ }^{4}$ Incidence and prevalence of male infertility according to the National Institutes of Health, male infertility is involved in approximately $40 \%$ of the more than 2 million infertile married couples in the United States.

One-half of these men experience irreversible infertility and cannot father children, and a small number of these cases are caused by a treatable medical conditions. Also, the data over in Indonesia reported that based on a study which was done five years ago. Tubal obstruction, with an incidence of $45.4 \%$ appeared to be the most prominent cause of infertility. The second most common factor was the poor quality of semen with $32.4 \%{ }^{3,4}$ Azoospermia was found in $12 \%$ of all semen samples and a sperm count below 5 million $/ \mathrm{ml}$ in $8.7 \%{ }^{1}$

Besides, In Bali itself The Ganesha Fertility Retreats aims to help couples to conceive using a 
holistic approach in a soothing environment. This retreat believes in providing the couples to be at best and optimal conditions to conceive a child. It takes twelve weeks to get the couples ready. Among the clients that join this retreat are from abroad. This also shows that the Balinese are open and want to participate in fertility aid. When the lifestyle is at its optimal, the success rates are enviable based on Jakarta Globe. Over the past 18 months, 86\% patients came for full program and did get successfully pregnant. This clearly shows that lifestyle has a great impact on conceiving a child. There is no age limit for male as they can father children throughout their life span. The sperm is manufactured in the testicles and it travels through the epididymis and vas deferens when ejaculated. But recently in 2011, in the Daily Mail, it was written that male over the age of 41 chances of becoming a father declines rapidly. It is also clearly seen that there are mainly few risk factors that greatly influence male for their infertility. Among the factors are age, hormonal imbalance and nutritional intake. But is seen that the major cause of infertility surge is the male lifestyle. ${ }^{5}$ Among the main lifestyle that believes to be a risk factor are cycling, injury to the groin, obesity, tight-fitting pants, anabolic steroids, alcohol, smoking, hot baths or sauna and finally the usage of laptop on the lap.

\section{METHOD}

This study used a descriptive cross-sectional design carried out during the 2017 period using a questionnaire given to respondents (male medical

\section{Table 1 Baseline Characteristics}

\begin{tabular}{lc}
\hline Characteristics & Percentage \\
\hline BMI (kg/m2) & \\
$<18.5$ (Underweight) & $6(5.2 \%)$ \\
18.5-24.9 (Normal) & $72(4.5 \%)$ \\
25-29.9 (Overweight) & $26(22.4 \%)$ \\
30-34.9 (Obese) & $4(3.4 \%)$ \\
35-39.9 (Severe obese) & $2(1.7 \%)$ \\
$>40$ (Morbidly obese) & $6(5.2 \%)$ \\
Monthly expenditure (Rupiah) & \\
$<1$ Million & $55(47.4 \%)$ \\
$<2$ Million & $39(33.6 \%)$ \\
$<3$ Million & $13(11.2 \%)$ \\
$<4$ Million & $7(5.2 \%)$ \\
$<5$ Million & $1(0.86 \%)$ \\
$<6$ Million & $1(0.86 \%)$ \\
Age (years) (Median-IQR) & $19(18-21)$ \\
\hline
\end{tabular}

student from semester III and V), a total of 116 male respondents were included in this study. Identification of lifestyle that can be a risk factor for infertility was investigated. Search carried out in the form of obese, laptop usage habits, smoking, alcoholism, injury to the groin area, history of mumps at childhood, and exercise habits. Data were analyzed using the SPSS version 25.0 program for windows, the data was displayed descriptively in table form.

\section{RESULT}

Subject characteristics data showed more students in the overweight category (22.4\%), then based on more monthly living costs with the usual life of fewer than 1 million rupiahs. The median age of the respondent is 19 years (Table 1).

Table 2 shows that knowledge of infertility is quite high in the respondents, but there are still several lifestyles as risk factors for infertility such as the use of laptops above the lap (29.3\%), smoking (1.7\%), alcohol consumption (11.2\%), groin injury (14.7\%). On the other hand there are still many respondents with low physical activity (sedentary lifestyle), activities in sports outside the home are still rare (29.3\%) (Table 3$)$.

\section{DISCUSSION}

It is known that mumps is a viral infection. It can give rise to testicles and leads to a condition called orchitis whereby there is inflammation and also causes the atrophy to the testicles. ${ }^{1,3}$ This on the other hand reduces the sperm production to reduce. It is lucky that complete sterility due to mumps is rare. Based on the study conducted in UNUD among the medical students from semester three and five respectively it is found that $17.2 \%$ have experienced mumps in their childhood.

Based on the study conducted on 483 males, the BMI was said unrelated to the sperm concentration, motility nor the morphology. It suggests that when the BMI is above 35 , which is severely obese and 40 being morbidly obese have higher based on the body mass index (BMI) status, chances of having a lower sperm count when compared to man with normal body weight. ${ }^{2,6}$ Based on the data collected, it is found that $1.7 \%$ and $5.2 \%$ are at risk for lower sperm count respectively for severe obesity and morbidly obese. Dietary modifications have been shown to improve infertility. Males, generally have greater semen parameter, is improved by diets consisting of limited processed meats and cheese and by increase low-fat dairy and fish. Imbalance of reactive oxygen sperm may increase in sperm DNA structural damage. ${ }^{3,6}$ Based on the questioner 
Table 2 Daily lifestyle that contributes to infertility

\begin{tabular}{lcc}
\hline Lifestyle risk factor & Yes & No \\
\hline $\begin{array}{l}\text { Knowledge on male infertility } \\
\text { Stress in campus }\end{array}$ & $100(86.2 \%)$ & $16(13.8 \%)$ \\
$\begin{array}{l}\text { Feeling depressed or lost of interest/ } \\
\text { sleeping often }\end{array}$ & $38(2.8 \%)$ & $67(57.8 \%)$ \\
$\begin{array}{l}\text { Family history with infertility } \\
\begin{array}{l}\text { Ever experience mumps in } \\
\text { childhood }\end{array}\end{array}$ & $9(7.8 \%)$ & $107(92.2 \%)$ \\
$\begin{array}{l}\left.\text { Obesity (BMI>30kg/m }{ }^{2}\right) \\
\begin{array}{l}\text { Consuming fast food on a daily } \\
\text { basis }\end{array}\end{array}$ & $20(17.2 \%)$ & $96(82.8 \%)$ \\
$\begin{array}{l}\text { Alcoholism } \\
\text { Active Smoker }\end{array}$ & $13(11.2 \%)$ & $108(93.1 \%)$ \\
$\begin{array}{l}\text { Using laptop on the lap (more than } \\
\text { one hour per usage) }\end{array}$ & $2(1.7 \%)$ & $102(87.9 \%)$ \\
$\begin{array}{l}\text { History of injury around the groin } \\
\text { region by (falling, being hit) }\end{array}$ & $34(29.3 \%)$ & $114(98.3 \%)$ \\
\hline
\end{tabular}

Table 3 Daily exercise activity

\begin{tabular}{lcc}
\hline Daily exercise habit & Yes & No \\
\hline $\begin{array}{l}\text { Weekly outdoor activities (doing exercise three } \\
\text { times a week/total of 150minutes) }\end{array}$ & $34(29.3 \%)$ & $82(70.7 \%)$ \\
Practise meditation (Yoga,breathing exercise) & $55(47.4 \%)$ & $61(52.6 \%)$ \\
Cycling outdoors (more than 30 miles) & $17(14.7 \%)$ & $99(85.3 \%)$ \\
\hline
\end{tabular}

distributed, $12.1 \%$ of medical students from UNUD of semester three and five consume fast food from the fast food outlets daily. Only $64.3 \%$ out of the 116 participants from semester three and five medical students from UNUD consume a well-balanced diet based on the Indonesian food pyramid

The strongest association between men alcohol into pregnancy and spontaneous abortion was seen when the consumption occurred closest to the time of semen collection. It is found that drinking at least four drinks per week decreases the chances of life conception. ${ }^{7}$ It is clear that only $11.2 \%$ out of the total participant in the study from semester 3 and semester 5 UNUD medical faculty is found to drink alcohol throughout the year. Approximately 35\% of reproductive age men in United States smoke cigarettes. If smoking is ceased, fecundity of the process of conception returns to a similar rate as nonsmokers within a year. Smoking is found to reduce the sperm concentration, total sperm count and total motile sperm. It is found that only $1.7 \%$ out of the whole study of males from semester three and five respectively have the habit of smoking more than 22 cigarettes a day. ${ }^{8}$

Usage of laptop on the lap for more than one hour per usage and going to the sauna often can lead to an increase of 5 degrees Fahrenheit per time. Increase in the scrotum temperature is caused by the heat released by the surrounding area of the scrotum for instance, the laptop and sauna. Based on a study, it is found that using laptops for more than 15 minutes on the lap in a room whereby the surrounding temperature is controlled can increase the scrotum temperature by 5 -degree Fahrenheit which is equivalent to 2.7 degrees Celcius. Usage of laptop on the lap also decreases the sperm concentration by $40 \%$ based on another survey. ${ }^{9-11}$ Based on the UNUD respondents from semester three and five medical students respectively it is found that $29.3 \%$ use their laptops on their laps for more than one hour.

\section{CONCLUSION}

It is wise to know the role of students to be aware of the lifestyles potential for male infertility.There is still a sedentary lifestyle among medical students who may develop into a risk factor for infertility.

\section{CONFLICT OF INTEREST}

The author declares there is no conflict of interest regarding publication of the manuscript.

\section{FUNDING}

Current study doesn't receive any specific grant from government or any private sectors

\section{ETHICAL ASPECT}

This study has been approved by Committee of Ethics in Faculty of Medicine Udayana University/ Sanglah General Hospital with ethical clearance reference number 254/UN.14.2/KEP/2016.

\section{REFERENCES}

1. Fahami F, Quchani SH, Ehsanpour S, et al. Lived Experience of Infertile Men With Male Infertility Cause. Iran J Nurs Midwifery Res. 2010;15(Suppl1):265-271

2. Foster R, DaCosta V, et al. Successful treatment of severe male factor infertility in Jamaica with intracytoplasmic sperm injection, West Indian Medical Journal. 2011;60(1):43-46.

3. Gaus DS, Talekar M, Pathak VP. Effect of cigarette smoking on semen quality of infertile men. Singapore Medical Journal. 2007;48(2):119-23.

4. Silva LF, Oliveira JB, Petersen CG, Mauri AL, Massaro FC, et al. The effects of male age on sperm analysis by motile sperm organelle morphology examination. Reprod Biol Endocrinol. 2012;10:19-25.

5. Robbins WA, Elashoff DA, Xun L, Jia J, Li N, Wu G. Effect of lifestyle exposure on sperm aneuploidy. Cytogenetic and Genome Research. 2005;111(4):371-7.

6. Afeiche MC, Gaskins AJ, Williams PL, Toth TL, Wright DL, Tanrikut C, et al. Processed meat intake is unfavorably and fish intake favorably associated with semen quality indicators among men attending a fertility clinic. J Nutr. 2014;144(7):1091-8. 
7. Eggert J, Theobald H, Engfeldt P. Effects of alcohol consumption on female fertility during an 18-year period. Fertil Steril. 2004;81(2):379-83.

8. Kunzle R, Mueller MD, Hanggi W, Birkhauser MH, Drescher H, Bersinger NA. Semen quality of male smokers and non-smokers in infertile couples. Fertil Steril. 2003;79(2):287-91.

9. Epstein YM, Rosenberg HS, Grant TV, Hemenway BAN Use of the internet as the only outlet for talking about infertility. Fertil Steril. 2002;78(3):507-14

10. Wise LA, Cramer DW, Hornstein MD, Ashby RK, Missmer SA. Physical activity and semen quality among men attending an infertility clinic. Fertil Steril. 2011;95(3):1025-30.
11. Nabi G, Amin M, Ali Khan AR. Reproductive health in rickshaw drivers: occupational exposure to environmental stressor. Bali Medical Journal. 2014;3(2):78-84. doi:10.15562/bmj.v3i2.79.

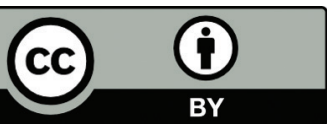

This work is licensed under a Creative Commons Attribution 